\title{
Notas sobre Ficção, Histórias de Vida e Pesquisa em Educação Matemática: A Propósito de 'O impostor', de Javier Cercas
}

\author{
Notes about Ficcion, Life Stories and Research in Mathematics \\ Education: Regarding the 'O impostor', by Javier Cercas
}

Filipe Santos Fernandes ${ }^{\mathrm{a}}$

a Faculdade de Educação, Universidade Federal de Minas Gerais, Belo Horizonte, Brasil - fernandesfs@ufmg.br

Palavras-chave: Educação matemática. Estética ficcional. Narrativa.

Keywords:

Mathematics education. Functional aesthetics. Narrative.
Resumo: "A realidade mata, a ficção salva" - afirma Javier Cercas ao propor um livro sobre a vida de Eric Marco, sindicalista espanhol que fingiu ter lutado na Guerra Civil Espanhola e vivenciado os horrores de um campo de concentração nazista. Articulando as inquietações de Javier Cercas para a escrita da obra e nosso interesse de relacionar a ficção, as histórias de vida e a pesquisa em Educação Matemática, buscamos neste texto evidenciar o conflitivo espaço da ficção e das histórias de vida na pesquisa e como determinados movimentos epistemológicos no campo da Educação Matemática permitiram uma reconfiguração desse espaço. Dessa discussão, propomos pensar os efeitos de uma estética ficcional na pesquisa em Educação Matemática, convidando-nos a um modo de fazer pesquisa em que a força, a fantasia, a imaginação, a memória e o amor pelas palavras participam intensamente da produção do conhecimento.

Abstract: "Reality kills, fiction saves" - that is what the author affirms when proposing a book about Eric Marco's life, a Spanish syndicalist who pretended to have fought in the Spanish Civil War and experienced the horrors of a Nazi concentration camp. Articulating the concerns of Javier Cercas about the writing of the book and our interests to relate fiction, life stories and research on Mathematics Education, we aim in this text to evidence the conflictive space of fiction as well as the life stories on research and how some of the epistemological movements in the Mathematical Education field allowed a reconfiguration of this own space. From this discussion, we aim to reflect upon the effects of a functional aesthetics to the research in Mathematical Education. 
1.

É possível narrar a história de vida de um homem que mentiu sobre um dos maiores crimes da humanidade? Uma história que, repleta de invenções, distorções e mentiras, atordoa a memória da Guerra Civil Espanhola e dos regimes totalitários europeus? Caberia narrar essa vida em meio a tantas farsas e dissimulações? Qual o sentido de dedicar tinta, páginas, papéis e palavras a um homem que enganou todo um país, que se fez herói na memória coletiva mais sensível de um povo?

Eric Marco, sindicalista que fingiu ter lutado na Guerra Civil Espanhol e vivenciado os horrores de um campo de concentração nazista, teve sua memória consagrada no mercado das histórias de vida. Recebeu medalhas e condecorações, sendo celebrado ao lado de grandes nomes que marcaram a história da Espanha no século XX. Apenas trinta anos depois, as incertezas sobre os acontecimentos narrados por Marco emergiram. De herói, Marco tornouse uma vergonha na memória da Espanha.

Ao considerarmos a obra $O$ Impostor, na qual o escritor espanhol Javier Cercas ${ }^{1}$ propõe contar a história de vida de Eric Marco, buscamos neste texto relacionar a ficção, as histórias de vida e a pesquisa em Educação Matemática. Nosso objetivo é evidenciar o conflitivo espaço da ficção e das histórias de vida na pesquisa e como determinados movimentos epistemológicos no campo da Educação Matemática permitiram repensar esse espaço, especialmente no âmbito das pesquisas sobre formação de professores e historiográficas.

O texto, como sugere seu título, é dividido em notas que articulam questões da pesquisa em Educação Matemática com leituras da obra de Javier Cercas (CERCAS, 2015). Os trechos em itálico e entre aspas são citações diretas da obra, constando apenas a referência à página. Essas notas permitiram uma discussão sobre os efeitos de uma estética ficcional na pesquisa em Educação Matemática, um modo de fazer pesquisa em que a força, a fantasia, a imaginação, a memória e o amor pelas palavras participam intensamente da produção do conhecimento.

\section{2.}

Na pesquisa em Educação Matemática, as narrativas têm contribuído com a construção das investigações de diferentes formas. Entrevistas, diários de campo, escritos biográficos e autobiográficos e tantas outras modalidades da narrativa foram convertidas em caminhos para

\footnotetext{
${ }^{1}$ Javier Cercas nasceu em Ibahernando, Cáceres, em 1962. Escritor premiado, seus livros foram traduzidos para mais de trinta línguas. Desde 1989, leciona Literatura Espanhola na Universidade de Gerona. É colaborador habitual na edição catalã do jornal El País.
} 
produção do conhecimento ao mesmo tempo em que permitiam o desenvolvimento da área de pesquisa.

Contudo, mesmo sendo evidente o uso das narrativas, as discussões sobre suas potencialidades na pesquisa em Educação Matemática são ainda recentes. Em momentos anteriores, as teorizações sobre seus usos figuravam como apropriações de outros campos, especialmente de vertentes da Educação ou da Filosofia, havendo um pequeno e quase inexpressivo espaço de problematização no qual educadores matemáticos discutiam como as especificidades de sua área de pesquisa, sobretudo seus objetos, problemas e anseios, colocavam em questão o conhecimento possível junto às narrativas mobilizadas. Tratava-se, então, da adoção de orientações teórico-metodológicas de outras áreas de pesquisa para aplicação em temáticas próprias da Educação Matemática, com poucas flexibilizações de procedimentos e de análise.

A reconfiguração desse cenário parece acontecer quando uma modalidade particular de narrativa, as histórias de vida de professores de matemática, passa a ganhar destaque no cenário da pesquisa em Educação Matemática do país. As intenções de registro, de compreensão e de valorização dessas trajetórias de vida acentuaram as preocupações envolvendo a produção do conhecimento junto a narrativas no campo da Educação Matemática, insinuando formas de pesquisar que têm como marca a necessidade de construção de procedimentos teórico-metodológicos singulares. Ainda que em diálogo com outros campos, esses procedimentos passaram a ser construídos por meio de questões próprias da Educação Matemática, respondendo às especificidades da área.

Seguindo os trabalhos de Gaston Pineau, Souza (2010, p. 17) entende a história de vida como uma denominação genérica "que se revela como pertinente para a compreensão do que cada um é, das aprendizagens que são construídas ao longo da vida, das experiências e de um processo de conhecimento de si e dos significados atribuídos aos diferentes fenômenos que mobilizam e tecem a vida individual/coletiva." Esses conhecimentos permitidos pelas histórias de vida ganham força, especialmente, nas pesquisas sobre formação de professores de matemática, buscando entrever nas trajetórias pessoais e profissionais sentidos da formação e da atuação desses docentes. Essas pesquisas, que antes davam centralidade a aspectos institucionais e/ou instrutivos, como modalidades de cursos ou prescrições curriculares, passam a considerar a subjetividade e os contextos dos professores na produção de conhecimentos sobre os processos formativos envolvidos na docência.

As histórias de vida marcam, então, um recomeço das narrativas na pesquisa em Educação Matemática. Inicialmente restritas a pesquisas sobre formação de professores e, mais adiante, ampliando sua participação em outras temáticas, as histórias de vida permitiram acentuar em pesquisadores em Educação Matemática preocupações sobre a mobilização das 
narrativas em suas pesquisas e do conhecimento possível junto a elas. Essa intensificação de preocupações conferiu um novo olhar não só para as trajetórias de vida, mas expandiu-se para outras modalidades narrativas, inclusive aquelas que eram usualmente negligenciadas pelas práticas de pesquisa mais gerais, como a literatura e a ficção.

Essa ampliação das fontes de dados - que envolve a incorporação de documentos pessoais (como correspondências, diários, escritos autobiográficos) e de construção biográfica (como entrevistas orais e/ou escritas) - veio acompanhada de um repensar das diferentes dimensões da pesquisa, e não só dos procedimentos de construção de dados. Passam a ser pautadas na Educação Matemática discussões envolvendo os desdobramentos epistemológicos dessa ampliação, como aportes teóricos, movimentos de análise e modos de apresentação e de publicação de resultados/compreensões.

A seguir, apresentamos um breve e descritivo panorama de dois grupos de pesquisa que têm se dedicado ao estudo das potencialidades das narrativas na pesquisa em Educação Matemática no Brasil ${ }^{2}$. Esses grupos, que têm em comum a utilização das histórias de vida para a elaboração de seus teorizações, participaram significativamente do recomeço das narrativas em Educação Matemática.

No âmbito da pesquisa sobre a formação de professores de matemática, ganham destaque as investigações do Grupo de Estudos e Pesquisas sobre Formação de Professores de Matemática (GEPFPM), sediado na Universidade Estadual de Campinas (UNICAMP). Criado no ano de 1999 por iniciativa de um grupo de pós-graduandos da área de Educação Matemática da Faculdade de Educação da UNICAMP, o Grupo tem o objetivo de estudar/construir aportes teórico-metodológicos para pesquisas sobre a formação e desenvolvimento profissional de professores de matemática. Atualmente, o GEPFPM é composto por pesquisadores de diferentes instituições de Ensino Superior do estado de São Paulo e é coordenado pelo professor Dario Fiorentini. ${ }^{3}$

Em sua atuação, o GEPFPM contribuiu em diversos momentos com trabalhos de sistematização das pesquisas sobre a formação de professores de matemática no Brasil. Um desses trabalhos, publicado em 2002, destaca uma virada paradigmática ocorrida na década 1990 que envolvia, por um lado, o conceito de professor reflexivo e, por outro, a conscientização de professores-formadores de que propostas de investigação sobre a formação de professores de matemática embasadas apenas aportes teórico-científicos reduziam sua complexidade e a pluralidade a aspectos instrutivos e técnicos, ignorando uma diversidade de

\footnotetext{
${ }^{2}$ Evidentemente, poderíamos indicar outros grupos de pesquisa nacionais e internacionais que participaram deste movimento de repensar as narrativas na pesquisa em Educação Matemática. Contudo, dada limitação do texto e a necessidade de aprofundarmos, mais à frente, em discussões que envolvem aspectos formativos e historiográficos, optamos por destacar a atuação de apenas dois deles.

${ }^{3}$ Maiores informações sobre o grupo podem ser consultadas em: <https://gepfpm.wordpress.com/>.
} 
dimensões da prática educativa. Segundo os pesquisadores do Grupo, essa virada paradigmática representou uma mudança de ordem epistemológica, especialmente em relação ao modo de produção do conhecimentos sobre/para a prática pedagógica (FIORENTINI et al., 2002).

Junto a essa virada paradigmática, diferentes pesquisas do GEPFPM compartem aspectos teórico-metodológicos que utilizavam histórias de vida para a elaboração de compreensões a formação e a atuação de professores de matemática. As investigações do Grupo passaram a adotar, em grande parte, a expressão professor que ensina matemática no lugar de professor de matemática, uma tentativa de expressar o deslocamento dos estudos tradicionalmente situados na formação inicial e continuada para cenários nos quais diferentes dimensões da vida de professores recebem destaque. Ganham relevo, assim, o estudo de saberes, conhecimentos, práticas, identidades, crenças e concepções de professores que, tendo ou não trajetórias de qualificação profissional em cursos de Matemática, atuam como docentes dessa disciplina.

O deslocamento promovido pelo GEPFPM permite elaborar considerações que são desdobramentos das preocupações de seus pesquisadores com a utilização de narrativas - em particular, das histórias de vida - para a construção de suas investigações. A título de exemplo, podemos citar o entendimento do Grupo de que a formação do professor que ensina matemática é um processo contínuo e sempre inconcluso que envolve não só a qualificação em cursos de licenciatura - o que pode, inclusive, não ter acontecido -, mas também vivências que se situam em momentos anteriores e posteriores a essa formação. Essa consideração é, evidentemente, perceptível em discussões mais gerais do campo da Educação, mas é especialmente sensível dados, entre outros aspectos, os processos históricos que marcam a formação e a atuação de professores que ensinam matemática, como a carência de profissionais, a implementação urgente e acelerada de programas de capacitação, ou as dimensões emocionais e comportamentais.

Considerando as marcas históricas da formação e da atuação de professores de matemática e o cuidado metodológico do uso de narrativas em pesquisas, ganham destaque no cenário nacional os trabalhos desenvolvidos pelo Grupo de Pesquisa História Oral e Educação Matemática (GHOEM), grupo interinstitucional sediado na Universidade Estadual Paulista “Júlio de Mesquita Filho" (UNESP) e liderado pelo professor Antonio Vicente Marafioti Garnica. ${ }^{4}$ Fundado em 2002, o Grupo tinha como proposta inicial exercitar as potencialidades da História Oral como metodologia para pesquisas em Educação Matemática, dedicando-se especialmente a trabalhos historiográficos que construíam procedimentos teórico-

\footnotetext{
${ }^{4}$ Maiores informações sobre o grupo podem ser consultadas em: <http://www2.fc.unesp.br/ghoem/>.
} 
metodológicos para mobilização da História Oral ao mesmo tempo em que desenvolviam investigações sobre processos históricos ligados à educação matemática. Nessas investigações, destacam-se histórias de instituições de formação e de atuação de professores que ensinam matemática (como universidades, escolas normais etc.) ou de programas de formação e/ou capacitação implementados a curto e médio prazo (como a CADES, Campanha de Aperfeiçoamento e Difusão do Ensino Secundário, que desenvolveu expressivo papel na formação de professores de matemática nas décadas de 1950 e 1960).

Com o passar do tempo, essa configuração foi alterada, ampliando-se de modo a incorporar outros temas e outras abordagens teórico-metodológicas. Pode-se dizer, hoje, que o interesse central do grupo é o estudo da cultura escolar e o papel da Educação Matemática nessa cultura. Assim, os temas dos inúmeros trabalhos desenvolvidos são variados, abordando a formação de professores de Matemática, as narrativas, a História Oral, os manuais didáticos, instituições de vários níveis e modalidades de ensino nos quais atuam professores de Matemática e dos quais a Matemática faz parte, a História da Educação Matemática, a análise de livros antigos e contemporâneos - didáticos ou não, formação e conservação de acervos etc.

Um ponto que merece destaque na atuação do grupo é o cuidado no uso das narrativas. Ao buscar por uma metodologia em processo, o grupo exercita diferentes caminhos teóricometodológicos, tateando as possibilidades e limitações da mobilização de uma determinada modalidade narrativa junto a determinada questão. Esse processo, contínuo e central, tem permitido a apresentação de trabalhos que rompem com as formas usuais de apresentação de trabalhos acadêmicos, rompendo de modo eticamente comprometido com as lógicas epistemológicas e estéticas tradicionais da academia.

Esses dois grupos guardam ao menos duas aproximações: a identificação de um trabalho formativo ou historiográfico que confere às narrativas construídas ou recebidas um papel central na elaboração de compreensões sobre a formação inicial ou continuada e a pluralidade de abordagens teórico-metodológicas, em uma diversificação terminológica positiva. Essas duas características marcam as preocupação desses grupos não só com a adoção de narrativas não usuais como fontes de dados para a pesquisas, mas a construção de caminhos teórico-metodológicos diferenciados nas pesquisas sobre a formação e atuação de professores de matemática e em história da educação matemática.

3.

Na primeira parte de $O$ Impostor, intitulada A pele da cebola, Javier Cercas oscila entre escritos que narram episódios da vida de Eric Marco e outros que se dedicam à 
compreensão da vontade e da tarefa de escrever um livro permeado pelo sentido de ficcionalidade que ronda a história do sindicalista.

A inquietação que se coloca ao escritor está na sua percepção de que as tentativas de construção de uma história da vida de Eric Marco enturvecem as fronteiras entre a história e o romance, entre o fato e a fabulação, entre a realidade e a ficção: "Não voltei mais a pensar em escrever sobre Eric Marco até quatro anos depois da explosão do caso [...]. Nessa ocasião, eu me encontrava em um estado lamentável e sentia que para sair dele precisava escrever um romance de ficção, uma história fictícia e não uma história real - a ficção salva, a realidade mata, eu repetia a mim mesmo -, e que minha história sobre Marco só poderia ser uma história real, pois Marco já fizera ficção demais de sua vida, e acrescentar mais ficção a essas ficções seria redundante, literalmente irrelevante; recordava, da mesma forma, os argumentos que, quatro anos antes, em uma noite de insônia em Madri, tinham me levado à decisão de abandonar o livro sobre Marco antes mesmo de começar a escrevê-lo.” (p. 29)

Por um lado, Javier Cercas parece convencido de que, naquela altura de seu ofício como escritor, era necessário dedicar-se a um livro de ficção. Por outro, via-se diante da necessidade de escrever uma obra na qual o principal personagem - um homem real, de "carne e osso" - era um impostor. Marco já era um personagem ficcional em nossa realidade, um farsante que incansavelmente construiu imagens de si mesmo. Qual seria o sentido de escrever uma ficção junto àquela história de vida? Qual o sentido de escrever uma ficção sobre outra ficção? Restava-lhe, então, escrever sobre o conflito entre a verdade e a mentira.

"Mas seria possível ir atrás disso? Seria possível apresentar a crônica da mentira de Marco como uma história verdadeira? [...] haviam opinado que nunca poderíamos chegar a verdade profunda de Eric Marco, mas não seria esse o melhor motivo para escrever sobre ele? Esse 'não saber' ou essa dificuldade de saber não seriam uma razão predominante para justamente procurar saber? E mesmo que o livro sobre Marco fosse um livro impossível, [...] não seria isso um estímulo perfeito para escrevê-lo? Não são os livros impossíveis os mais necessários, talvez os únicos que valem realmente a pena tentar escrever?” (p. 56)

Para a história de um mentiroso fenomenal procurou seguir por uma escrita em idas e vindas, em acasos e necessidades, evidenciando as dúvidas morais, éticas, políticas e existenciais que permeavam os encontros com os fatos da vida de Eric Marco. Não se tratava mais de escrever um livro sobre Eric Marco, mas de escrever um livro com Eric Marco, transformando sua história em um campo de batalha que exercitava os limites de um escritor e de sua escrita. Em entrevista ${ }^{5}$ para o jornal Folha de São Paulo, Javier Cercas conta: "Eu não

\footnotetext{
${ }^{5}$ Entrevista concedida a Sylvia Colombo, em 17 de maio de 2015. Disponível em:

$<$ http://sylviacolombo.blogfolha.uol.com.br/2015/05/17/somos-todos-impostores-uma-entrevista-com-javier-

cercas/>. Acesso em 29 set. 2017.
} 
escrevo romances de aventura, mas sim sobre a aventura de escrever romances, não conto apenas as histórias, mas também o processo. Nesse caso [o da escrita do livro O impostor], mais do que nunca. Não quero que o leitor leia meus livros, achem a história fantástica, mas que elas não têm nada a ver comigo. Quero meter o leitor dentro e para isso preciso meter-me dentro também."

Assim, o autor não procurou mobilizar a história de Eric Marco para justificá-lo ou, como defendiam alguns, para mostrar como suas mentiras produziram uma consciência histórica e memorialística que tocou a muitos espanhóis. Afinal, argumentavam, "Dissera coisas que não eram reais, sim, enfeitara, maquiara ou modificara um pouco a verdade, sim, mas não o fizera por egoísmo e sim por generosidade, não por vaidade e sim por altruísmo, para formar as novas gerações dentro da lembrança do horror, para resgatar a memória histórica daquele país amnésico, ele fora um grande impulsionador, se é que não fora o principal impulsionador, do resgate da memória da Espanha, da memória das vítimas da guerra e do pós-guerra, do franquismo, do fascismo e do nazismo [...].” (p. 38)

O autor, contudo, parece não aceitar que sua obra recaia em uma tentativa de justificar a vida de Eric Marco, mas de impedir a existência de um novo Marco. Isso não quer dizer, contudo, que busca desmascará-lo, mas evidenciar o conflitivo jogo que se constitui na relação da vida e sua expressão em uma forma narrativa, entre a vida vivida e a vida contada.

4.

Como buscamos pontuar, as histórias de vida, ao serem convertidas em fontes de dados, permitiram um recomeço da mobilização das narrativas na pesquisa em Educação Matemática. Transcrições e textualizações de entrevistas, diários de campo, escritos biográficos e autobiográficos, acervos pessoais e tantos outros procedimentos ou formas de registro que permitiam a construção ou a recepção de narrativas tornaram-se fontes para a pesquisa em Educação Matemática, dispondo informações e sentidos que seriam mobilizados na elaboração de compreensões em torno de diferentes temáticas.

Contudo, não se pode pensar que essa adoção das histórias de vida como fontes de dados tenha sido marcada apenas por um sentido positivo em relação às novas modalidades de pesquisa que emergiam, já que ela foi também alvo de questionamentos pautados em critérios de cientificidade já estabelecidos no campo de pesquisa em Educação Matemática.

O ponto central desses questionamentos estava relacionado com a possível existência de impostores, afinal, como verificar a veracidade dos fatos narrados nas histórias que passariam a compor essas pesquisas? E se, nas pesquisas sobre formação e atuação docente, os professores falseassem suas concepções e práticas? E se inventassem episódios, fantasiassem alunos que nunca existiram ou construíssem situações que nunca aconteceram? 
E se, mesmo procurando dizer a verdade, a memória enganar, confundir, driblar o passado? Haveriam histórias reais ou contos, historietas, fábulas? Que cientificidade haveria nisso? Mediante tais questionamentos e outros, passou-se à necessidade de revisitar os critérios de cientificidade que sustentavam essas pesquisas, afirmando as histórias de vida como fontes legítimas para elaborar compreensões sobre a formação e atuação de professores de matemática em uma perspectiva formativa ou historiográfica.

Ao adotar procedimentos ou formas de registro para a construção ou recepção dessas histórias de vida, foi necessário estabelecer um conjunto de entendimentos sobre as possibilidades e os limites dessa utilização. Esse conjunto de entendimentos veio acompanhado de cuidados que permitiram operacionalizar e validar essas narrativas como fontes legítimas para a produção do conhecimento junto aos paradigmas científicos por ela firmados - ou, em outras palavras, pretender o uso das histórias de vida "sem deixar de ser pesquisa". Segundo Souza (2013, p. 260), a "ampliação de fontes traz, junto, a necessidade de um repensar metodológico, mas ambos os esforços se estruturam sobre um alicerce de pressupostos teóricos, uma visão de mundo."

Na perspectiva formativa considerou-se que as histórias de vida traziam importantes elementos para compreender e avaliar questões ligadas à formação e à atuação de professores de matemática, sendo o relevo das investigações dado a diferentes aspectos da vida dos professores. Da relevância anterior dos elementos de uma vida que poderiam ser comprovados, como aspectos técnicos derivados de sua formação inicial ou continuada, passou-se a observar outros aspectos que permitiam uma articulação entre o individual e o coletivo, entre a vida de um sujeito e o campo social no qual está inserido.

Assim, a existência de impostores deixou de ser um ponto de questionamento nessas investigações, já que a produção do conhecimento não estava necessariamente ligada ao que o sujeito narrava, mas às possíveis articulações entre as narrativas individuais e o que foi narrado por outros sujeitos ou delineado pelos discursos de um contexto social mais amplo. Essas articulações permitiam ressignificar as problemáticas colocadas à formação de professores, afirmando ou conflitando os discursos sobre a educação e possibilitando, muitas vezes, o desenho de orientações técnicas para a formação, como modalidades de cursos ou prescrições curriculares. Ainda que sejam possíveis os impostores, os sujeitos e suas vidas tal como nas argumentações de defesa de Eric Marco - permitiam a atenção a problemáticas que, antes, moravam na amnésia do discurso educacional, impulsionando a produção de ideias e ações.

Se na perspectiva formativa a discussão seguia pela afirmação da história de vida como meio para a produção do conhecimento educacional, nas pesquisas historiográficas a presença das histórias de vida ganhava uma dimensão mais conflitante. Isso porque há uma 
forte herança da separação entre história, memória e literatura pautada, especialmente, nos métodos empregados pela história científica - que, em um plano geral, valorizavam os documentos escritos - e na profissionalização do oficio do historiador - que se diferenciaria do poeta, do memorialista ou do romancista.

Posto que a adoção dos procedimentos ou formas de registro nas pesquisas historiográficas em Educação ameaçavam e desestabilizavam os modos tracionais de "fazer história", foi necessário construir fundantes epistemológicos que dessem suporte a essas pesquisas. As novas orientações seguiam, então, pela possibilidade de considerar a memória como meio legítimo de produção do conhecimento.

Um ponto a se observar é a construção da ideia de plausibilidade. Nela, cabe ao pesquisador, a partir de uma variedade de informações decorrentes dessas memórias, indagarse sobre a pertinência do que foi narrado, aproximando ou distanciando essas informações daquelas obtidas em outras fontes e elaborando uma leitura plausível junto àquilo que o sujeito diz. Esse processo, contudo, não tem a pretensão de questionar a veracidade da memória registrada, mas entender os atores desse cenário como "participantes contaminados por suas intenções, seus sonhos, seus princípios; impregnados por um estado de coisas, uma situação, um momento, tempo e espaço.” (GARNICA, 2010, p. 296)

É importante pontuar que valorização das histórias de vida em suas singularidades e sua leitura do ponto de vista da plausibilidade não exclui ou impossibilita a compreensão de um contexto mais amplo que envolve questões de ordem social, cultural, política e outras. Como destaca Souza (2013, p. 206):

\begin{abstract}
Admitir essas singularidades, a ação criativa e construtiva da narrativa, as experiências pessoais como fontes de pesquisa trazem um cuidado importante: a lembrança constante de que toda experiência narrada está inscrita em um contexto social e político. Esse cuidado é fundamental para que as pesquisas envolvendo narrativas as apresentem e avancem em termos de análise, não se restringindo a criar espaços para divulgação de práticas dos entrevistados. Em outras palavras, a singularidade das narrativas não deve impedir um estudo contextualizado, pois esse não precisa ser feito em busca de padrões e generalizações.
\end{abstract}

Nesse sentido, as perspectivas formativa e historiográfica que movem as pesquisas que utilizam as histórias de vida como fontes de dados devem levar em consideração que essas narrativas constituem-se em uma cronologia própria e em meio a construções e idealizações que envolvem a memória e a experiência. Não se trata de considerar as narrativas segundo um critério que a aproxima ou a distancia de uma verdade com pretensões de universalidade, mas admitir a participação intensiva e produtiva da singularidade, da ação criativa e das experiências pessoais no movimento de fazer pesquisa. 
5.

Na segunda parte do livro, $O$ romancista de si mesmo, novos enfrentamentos na escrita da história de Eric Marco surgem para Javier Cercas. E se as razões que levaram Marco a mentir fossem deixadas de lado e pudéssemos supor, mesmo que por um instante, que suas mentiras fossem altruístas e pedagógicas, que não mentiu por necessidade de admiração? “Marco mentia usando a verdade?”, ou, em outras palavras, "Marco dizia a verdade sobre a história (a história dos campos nazistas ou, no caso, a história da guerra e do pós-guerra espanhóis) apesar de mentir quanto ao lugar ocupado e ao papel desempenhado por ele nela?" (p. 201-202) "Seria Marco um romancista, e suas verdades e mentiras, portanto, da ordem do novelesco e não do histórico?” (p. 217)

Propondo tais questões, Javier Cercas quer chegar a uma pergunta que, em sua visão, deve ser anterior às demais: uma ficção seria, afinal, uma mentira? Diz o autor: “[...] ninguém, ou quase ninguém, tem dúvida de que as ficções propõem uma verdade: uma verdade fugidia, profunda, ambígua, contraditória, irônica e elusiva, uma verdade não factual mas moral, não concreta mas universal, não histórica ou jornalística, mas literária ou artística; muitos, porém, negam que essas ficções sejam mentira.” (p. 218)

Junto a essa consideração, Javier Cercas convida Górgias, citado por Plutarco: “A poesia [ou seja, a ficção] é um engano no qual quem engana é mais honesto do que quem não engana, e quem se deixa enganar mais sábio do que quem não se deixa enganar.” Dessa frase, o autor destaca duas palavras: "honesto" e "sábio". Por um lado, "honesto" leva a pensar que "o dever moral do autor de ficção consiste em enganar, para construir mediante ao engano a fugidia, ambígua e elusiva verdade da ficção"; por outro, "sábio" faz considerar que "o dever intelectual do espectador da ficção consiste em se deixar enganar, a fim de captar a profunda, irônica e contraditória verdade que o autor construiu para ele." De tudo isso, conclui: "A ficção é, portanto, uma mentira, um engano; [...] trata-se de uma mentira, ou de um engano, que, em um romance, não procura prejudicar quem é enganado, o qual somente acreditando nessa mentira ou nesse engano poderá chegar a uma verdade específica: a verdade da literatura.” (p. 219)

Entretanto, seriam as mentiras de Marco esse tipo de mentira? Seria ele um autor de ficção, uma espécie de romancista de si mesmo? Se sim, que verdade fugidia, ambígua e elusiva emerge de sua ficção? "O resultado de uma mistura entre uma verdade e uma mentira é sempre uma mentira, a não ser nos romances, onde ela é uma verdade. Marco confundiu de propósito os romances e a vida: deveria misturar verdades e mentiras nos primeiros, não na segunda; deveria ter escrito um romance. Se tivesse escrito um romance, talvez não teria feito o que fez. Talvez ele seja um romancista frustrado. Ou talvez não seja, e talvez não tenha se contentado com a ideia de escrever um romance e preferisse vivê-lo. Marco fez da sua vida 
um romance.” (p. 222) Talvez, o desejo de Marco não era transformar a realidade em ficção, mas sim a ficção em realidade: não quer escrever um romance, mas vivê-lo, protagonizá-lo.

Uma questão que chama a atenção na discussão de Javier Cercas é a figura do romancista e sua relação com a vida. Para o autor, romancista é aquele insatisfeito com a vida, que a reconstrói de acordo com seus desejos e que, mediante o uso das palavras, busca proteger ou até mesmo se curar da realidade. "A realidade mata o romancista e a ficção o salva, porque a ficção não é nada mais, frequentemente, que uma maneira de mascarar a realidade.” (p. 220)

Nesse movimento, o romancista inventa para si vida fictícia, "para esconder a sua vida verdadeira e viver uma vida diferente, para processar as vergonhas, horrores e insuficiências da vida real e transformá-los em ficção, para ocultá-los de si mesmo e dos outros.” (p. 220) O romancista produz e se produz construindo ficções que misturam "aquilo que realmente aconteceu com aquilo que ele gostaria que tivesse acontecido ou que lhe parecesse mais interessante ou mais apaixonante que tivesse acontecido, mas não aconteceu.” (p. 220) O romancista inventa em profundidade e, nessa tarefa, precisa ter "força, fantasia, imaginação, memória e, antes de mais nada, amor pelas palavras [...].” (p. 220)

\section{6.}

Em que medida as histórias de vida que compõem nossas pesquisas são histórias de sujeitos que desejam, assim como Marco, protagonizar um romance? Em que medida não construímos histórias próximas da ficção e, portanto, mentiras que servem a uma fugidia, ambígua e elusiva verdade? Quanto misturamos de verdades e mentiras visando produzir enganos que não prejudicam quem é enganado; enganos que, apenas quando acreditados, podem conduzir a verdade que buscamos produzir? Seríamos nós romancistas frustrados?

Ao mobilizarmos histórias de vida na pesquisa em Educação Matemática temos atuado, em alguma medida, como romancistas. Mediante o uso de palavras, revelamos desejos, encabulações, perplexidades e insuficiências de uma realidade que julgamos ser o mundo. Transformamos essas disposições em linguagem e, com isso, misturamos o que aconteceu com aquilo que gostaríamos que tivesse acontecido, uma realidade mais interessante e mais apaixonante. Buscamos redesenhar a realidade que nos encanta, que nos assombra, que nos ruboriza, que nos passa. Nossas matérias, como pesquisadores, são a força, a fantasia, a imaginação, a memória e, antes de mais nada, o amor pelas palavras.

Assim, a pesquisa em Educação Matemática, ainda que não seja um romance, tem algo que com ele compartilha: a possibilidade de uma estética ficcional (SILVA; VIOLA DOS SANTOS, 2012). Dotar a pesquisa de uma estética ficcional significa conferir ao pesquisar um estatuto de verdade que se afasta daquilo que está escrito - como na busca incessante pela 
veracidade do narrado - e que se aproxima de uma verdade fugidia, ambígua e elusiva que, apenas por meio da relação com outras verdades fugidias, ambíguas e elusivas, pode ser sustentada. Trata-se, então, de pensar as pesquisas de modo que a narrativa não é compreendida no âmbito da palavra, mas da relação com a palavra - ou, reforçamos, o que nos encanta, o que nos assombra, o que nos ruboriza, o que nos passa. ${ }^{6}$

É nesse sentido que se dá a importância da superação da dicotomia realidade/ficção como impedimento para produção do conhecimento. Em um dos textos do terceiro volume de Ditos e Escritos está a passagem em que Foucault (2009), ao comentar sobre seu temor quando da necessidade de retomar a ideia de ficção em seus trabalhos, propõe uma série de questões:

Para essa palavra ficção, várias vezes trazida, depois abandonada, e preciso voltar finalmente. Não sem um pouco de temor. Porque ela soa como um termo de psicologia (imaginação, fantasma, devaneio, invenção etc.). Porque parece pertencer a uma das duas dinastias do Real e do Irreal. Porque parece reconduzir - e isso seria tão simples após a literatura do objeto - as flexões da linguagem subjetiva. Porque ela oferece tanta apreensão e escapa. Atravessando, de viés, a incerteza do sonho e da espera, da loucura e da vigília, a ficção não designa uma série de experiências às quais o surrealismo já havia emprestado sua linguagem? [...] Mas e se essas experiências, pelo contrário, pudessem ser mantidas onde estão, em sua superfície sem profundidade, nesse volume impreciso de onde elas nos vêm, vibrando em torno do seu núcleo indeterminável, sobre seu solo que é uma ausência de solo? E se o sonho, a loucura, a noite não marcassem o posicionamento de nenhum limiar solene, mas traçassem e apagassem incessantemente os limites que a vigília e o discurso transpõem, quando eles vêm até nós e nos chegam já desdobrados? Se o fíctício fosse, justamente, não o mais além, nem o segredo íntimo do cotidiano, mas esse trajeto de flecha que nos salta aos olhos e nos oferece tudo o que aparece? (FOUCAULT, 2009, p. 68)

Ao propor ao fictício esse "trajeto de flecha que nos salta aos olhos e nos oferece tudo que aparece" sobre um solo "que é uma ausência de solo", o autor parece considerar a ficção como a apreensão provisória de uma multiplicidade que não é menos verdadeira de que qualquer outra apreensão e que, por isso, não joga com os sentidos de verdade próprios do pensamento moderno. A ficção é "a nervura verbal do que não existe, tal como ele é" (FOUCAULT, 2009, p. 69); de um modo que "nosso mundo real é tão ficcional quanto se queira, da mesma forma que nosso mundo ficcional é tão real quanto se possa imaginar" (SILVA; VIOLA DOS SANTOS, 2012, p. 121).

Uma estética ficcional não está, então, na escrita das histórias de vida que são convertidas em fontes de dados para nossas pesquisas, mas no conjunto dos diferentes regimes segundo o qual a narrativa é contada; na "trama de relações estabelecidas, através do

\footnotetext{
${ }^{6}$ Neste texto, trazemos uma discussão conceitual articulando a estética ficcional, a ficção segundo Michel Foucault e as pesquisas em Educação Matemática que mobilizam histórias de vida. A tese de Fernandes (2014) busca, além da discussão conceitual, exercitar a perspectiva da estética ficcional para a elaboração de compreensões sobre a Educação Matemática como área de pesquisa, construindo cinco histórias ficcionais que buscam, por meio da força, da fantasia, da imaginação, da memória e do amor pelas palavras, tratar de questões da Educação Matemática que surgiam no movimento de produção da tese.
} 
próprio discurso, entre aquele que fala e aquele do qual ele fala" (FOUCAULT, 2009, p. 210). Trata-se, portanto, um processo relacional situado:

[...] [na] postura do narrador em relação ao que ele narra (conforme ele faça parte da aventura, ou a contemple como um espectador ligeiramente afastado, ou dela esteja excluído e a surpreenda do exterior); [na] presença ou ausência de um olhar neutro que percorra as coisas e as pessoas, assegurando sua descrição objetiva; [no] engajamento de toda a narrativa na perspectiva de um personagem, de vários, sucessivamente, ou de nenhum, em particular; [no] discurso repetindo os acontecimentos a posteriori ou duplicando-os à medida que eles se desenrolam etc. (FOUCAULT, 2009, p. 210)

Pensar uma estética ficcional para a pesquisa em Educação Matemática é constituir uma relação em que a linguagem não é a aproximação da coisa à palavra, sua redutibilidade em um modelo representacional, mas uma relação que, no uso da linguagem, expõe, dispersa, reparte e abre essa distância. É a linguagem que busca exacerbar os desejos, as encabulações, as perplexidades e as insuficiências de uma realidade que nos atravessa. Diz Foucault, então, que "não há ficção porque a linguagem está distante das coisas, mas a linguagem é sua distância [...]; é qualquer linguagem que, em vez de esquecer essa distância, se mantém nela e a mantém nela, qualquer linguagem que fale dessa distância avançando nela é uma linguagem de ficção" (FOUCAULT, 2009, p. 69. Grifo nosso).

Portanto, dizemos que as pesquisas em Educação Matemática que mobilizam histórias de vida estão próximas de uma estética ficcional não porque há a possibilidade de invenção de personagens, cenários, situações ou tramas, mas na medida em que são inventados critérios de estilo próprios para explorar essa distância: uma distância entre as palavras e as coisas, entre as narrativas dos colaboradores e outras narrativas, entre quem fala e aquilo que se diz. A força, a fantasia, a imaginação, a memória e o amor pelas palavras não são a estética ficcional, mas o modo mais antigo e, talvez, mais direto de explorar essa distância.

Praticamos uma estética ficcional, essa relação de amor pela palavra, em "um exercício de amalgamar a ficção que o outro é à ficção que somos nós" (SILVA; VIOLA DOS SANTOS, 2012, p. 117), explorando, talvez, uma distância existencial. Como produto disso, materialidade dessa relação, temos pesquisas que se colocam na direção de produção de distanciamentos: textos que esperam desvelar abismos, histórias que não negligenciam a experiência e que combinam diferentes planos de significação e de sentido, movimentos de palavras que se prestam a diversas interpretações.

\section{7.}

"Marco é o que todos nós somos, mas de uma forma exacerbada, maior, mais intensa e mais visível, ou talvez ele seja todos os homens, ou talvez não seja ninguém, um grande recipiente, um conjunto vazio, uma cebola da qual se retiram todas as camadas da pele e não 
sobrou nada, um lugar para onde todos os significados confluem, um ponto cego através do qual se vê tudo, uma escuridão que ilumina tudo, um enorme silêncio eloquente, um vidro que reflete o universo, um vazio que tem a sua forma, um enigma cuja derradeira solução é que ele não tem solução, um mistério transparente que no entanto é impossível decifrar, e talvez que seja melhor que não se decifre.” (p. 448)

Apresentando essas inquietações, Javier Cercas caminha para o fim da obra sobre a vida de Eric Marco. O que está em jogo nesse momento é a relação entre a memória, a narrativa e a verdade. Como disse na entrevista acima citada, "Marco é uma hipérbole monstruosa do que somos. A literatura é isso, cria hipérboles monstruosas dos seres humanos. A literatura quer descrever tudo o que é do ser humano, e para descrever e para que o possamos ver, cria essas hipérboles monstruosas, exageros monstruosos para mostrar-nos o que somos."

Ao que parece, Cercas cria certa admiração por Marco. Não uma admiração que buscaria justificar suas invenções e dissimulações sobre a Guerra Civil Espanhola ou sobre os campos de concentração nazistas, mas para entendê-lo. "Entender não significa, é claro, perdoar ou [...] justificar; melhor ainda: significa justamente o contrário. O pensamento e a arte [...] procuram explorar aquilo que somos, revelando a nossa infinita, ambígua e contraditória diversidade, cartografando, assim, a nossa natureza. [...] porque o dever da arte (ou do pensamento) consiste em mostrar-nos a complexidade da existência, a fim de nos tornar mais complexos [...]" (p. 19).

São entendimentos como esses que permitem Javier Cercas afirmar: somos todos impostores...

8.

Seríamos nós, então, impostores? Seríamos romancistas frustrados que, com amor pela palavra, buscam expressar desejos, encabulações, perplexidades e insuficiências de nossa realidade? Nossas pesquisas, assim como a literatura, criariam hipérboles monstruosas dos seres humanos? Ao fazer pesquisa fazemos ficções do mundo e de nós mesmo? E, se fazemos, que verdade fugidia, ambígua e elusiva buscamos construir?

Acreditamos que duas discussões podem produzir alívios para essas inquietações. A primeira está relacionada às verdades fugidias, ambíguas e elusivas que buscamos construir por meio de nossas pesquisas. Ao adotarmos as histórias de vida como fontes de dados, propomos questões e interpretações que, no limite, criam entendimentos e produzem um solo de verdades pelo qual transitamos. Essas verdades não são, entretanto, verdades que pretendem universalidade, entendimento pleno ou que se situam na dicotomia fato/falsificação: por serem fugidias, escapam com rapidez de determinismos que poderiam 
localizá-las junto a uma pretensa de realidade; por serem ambíguas, abrem-se a diferentes sentidos e significados; por serem elusivas, provocam dificuldade de explicação e entendimento, exigindo cuidado, paciência e disposição.

De tal modo, defendemos que as pesquisas em Educação Matemática que mobilizam histórias de vida não construam para si o compromisso de compreender ou justificar essas vidas mediante um conjunto de elementos que as atravessam, mas de criar condições para impedir retornos: o retorno de uma vida para a justificar a vida de outros; o retorno de juízos para explicar, compreender, situar e, enfim, afirmar políticas de identidade.

O exercício de distanciamento que sugere Foucault (2009) - e que se torna, aqui, potente para pensar uma estética ficcional para a pesquisa em Educação Matemática - procura criar condições para dispersar a aproximação entre a história de vida e a vida. As histórias mobilizadas em nossas pesquisas não são as vidas daqueles que as narram e, por isso, as compreensões sobre a Educação Matemática que essas histórias de vida trazem - ou, as compreensões possíveis em nossas leituras - não são a Educação Matemática praticada, vivenciada ou defendida por cada um deles. Se a vida é numericamente uma, mas expressivamente múltipla, interessa-nos como subsiste em cada leitura de uma história de vida a possibilidade de expandir para além das identificações já traçadas, das imagens de sujeito já delineadas; de impedir retornos que nos levam a explicar, a compreender ou a justificar aquela vida entre as demais.

Pensar a pesquisa junto à estética ficcional é, então, fazer da escrita um espaço povoado por enredos, personagens e narradores; um emaranhado de sujeitos, lugares e tempos que, em um movimento de composição e recomposição, permitem histórias. Uma estética em que se narra sem julgamentos, hipóteses ou teses, mas que se compromete ética e esteticamente com o novo, afirmando positivamente suas potencialidades e entraves: trata-se de impedir retornos e de permitir novos começos. Um movimento em que as narrativas de vidas, ao nos atravessar, constituem a nossa história, permitindo que em um mesmo cenário surjam "aspectos sociológicos, antropológicos, culturais, literários, pictóricos; [...] monstros, mitos, doenças, autores consagrados e desconhecidos, crimes e castigos, metáforas ansiedades, angústias, referências sagradas e profanas [...].” (GARNICA, 2008, p. 112)

Nossas compreensões sobre a mobilização das histórias de vida na pesquisa em Educação Matemática abrem a possibilidade de pensar em movimentos de investigação em que a centralidade não está na análise minuciosa e detalhada da narrativa visando reconhecêla, compreendê-la ou justificá-la. Contudo, essa abertura deve estar atenta a dois compromissos, como aqueles determinados por Javier Cercas ao tratar da ficção: um compromisso moral e um intelectual. 
Por um lado, ainda que possa parecer estranho e muito pouco virtuoso, nosso compromisso moral é enganar, supondo que as vidas que mobilizamos em nossas pesquisas dizem das vidas vividas e que, consequentemente, as compreensões que elaboramos são legítimas para a construção de entendimentos sobre a Educação Matemática. Ainda que aceitemos que a construção da história de vida pelo sujeito não é o sujeito e tampouco sua vida a ela redutível, é apenas na afirmação dessa construção como verdade fugidia, ambígua e elusiva que podemos fazer operar nossos desejos, encabulações, perplexidades e insuficiências sobre uma realidade que dá solo às questões de pesquisa que formulamos.

[...] o homem que se conta não é o mesmo homem que vive, mesmo quando narra sua própria vida. Quando faz memória ou autobiografia, o sujeito narrador não coincide com o sujeito narrado, o sujeito da narrativa não é o mesmo personagem contado. Porque o sujeito da narrativa é um sujeito em estado de vida, em carne e osso, é um sujeito em que corre sangue nas veias. Já o sujeito narrado é um sujeito em estado de palavra, é feito de papel, é um sujeito em que corre tinta nas veias. (ALBUQUERQUE JR., 2011, p. 254)

Por outro lado, há um compromisso intelectual assumido por nossos leitores - ou, de um modo mais amplo, pelos interlocutores em nossa área de pesquisa - que consiste em se deixar enganar, em participar de um jogo a fim de apreender a profunda, irônica e contraditória verdade que construímos. Esse se deixar enganar não quer dizer uma aceitação ingênua das elaborações produzidas, mas uma disposição a compreender novos modos de produção do conhecimento, revisitando os paradigmas de investigação, os métodos, os processos e procedimentos, os critérios de legitimação, de qualidade e de validação dos resultados. Trata-se, enfim, de acreditar que as ficções permitem efeitos de verdade que conferem alívios para o que entendemos como nossa realidade.

Esses dois compromissos fazem reafirmar Javier Cercas: “a realidade mata, a ficção salva”. Por isso acreditamos que o principal objetivo de mobilizar histórias de vida na pesquisa em Educação Matemática é criar condições para impedir os tantos retornos que nos atravessam e impõem as determinações de quem somos, promovendo novos começos. Nessa abertura, a estética ficcional pode ser uma aliada, permitindo que a força, a fantasia, a imaginação, a memória e o amor pelas palavras participem intensamente da produção do conhecimento em Educação Matemática, revisitando o já dito e consentindo o novo, o que tem ainda um pequeno começo. Afinal, "a linguagem da ficção se insere em uma linguagem já dita, em um murmúrio que nunca começou.” (FOUCAULT, 2009, p. 70. Grifo nosso)

\section{Referências}

ALBUQUERQUE JR., D. M. Em estado de palavra: quando a história não consegue que se meta fora a literatura. In: FLORES, M. B. R.; PIAZZA, M. F. F. (Orgs.). História e arte: 
movimentos artísticos e correntes intelectuais. Campinas: Mercado de Letras, 2011. p. 249261.

CERCAS, J. O impostor. Tradução de B. Ajzenberg. São Paulo: Biblioteca Azul, 2015.

FERNANDES, F. S. A quinta história: composições da Educação Matemática como área de pesquisa. Tese de doutorado em Educação Matemática - Universidade Estadual Paulista "Júlio de Mesquita Filho", Rio Claro, 2014.

FIORENTINI, D.; NACARATO, A. M;. FERREIRA, A. C.; LOPES, C. S.; FREITAS, M. T. M.; MISKULIN, R. G. S. Formação de professores que ensinam matemática: um balanço dos 25 anos da pesquisa brasileira. Educação em Revista, n. 36, p. 137-160, dez. 2002.

FOUCAULT, M. Estética: literatura e pintura, música e cinema. Tradução de I. A. D. Barbosa. 2. ed. Rio de Janeiro: Forense Universitária, 2009. (Coleção Ditos e Escritos, III)

GARNICA, A. V. M. Outras inquisições: apontamentos sobre História Oral e História da Educação Matemática. Zetetikè, v. 18, n. 34, p. 259-304, jul./dez. 2010.

GARNICA, A. V. M. A experiência do labirinto: metodologia, história oral e educação matemática. São Paulo: UNESP, 2008.

SILVA, H.; VIOLA DOS SANTOS, J. R. Sobre teorização, estética ficcional e algumas aproximações entre o Modelo dos Campos Semânticos e a História Oral. In: ANGELO, C. L. et al. (Orgs.). Modelo dos Campos Semânticos e Educação Matemática: 20 anos de história. São Paulo: Midiograf, 2012. p. 110-128.

SOUZA, E. C. Pesquisa narrativa, (auto)biografias e história oral: ensino, pesquisa e formação em Educação Matemática. Ciências Humanas e Sociais em Revista, v. 32, n. 2, p. 13-27. 2010.

SOUZA, L. A. Narrativas na investigação em História da Educação Matemática. Revista de Educação PUC-Campinas, v. 18, n. 3, p. 259-268, set./dez. 2013.

\section{SOBRE O AUTOR}

FILIPE SANTOS FERNANDES. Doutor em Educação Matemática pela Universidade Estadual Paulista "Júlio de Mesquita Filho" (UNESP/Rio Claro). Professor da Faculdade de Educação da Universidade Federal de Minas Gerais. Membro do Grupo de Pesquisa História Oral e Educação Matemática (GHOEM) e do Núcleo de Estudos e Pesquisas em Educação do Campo (NEPCampo). Atua em pesquisas em História da Educação Matemática e em temáticas que relacionam a Educação Matemática e a Educação do Campo. 